\title{
Microplastic Pollution in Inland Waters Focusing on Asia
}

\author{
Chenxi Wu, Kai Zhang, and Xiong Xiong
}

\begin{abstract}
The presence of microplastics in marine environment is increasingly reported and has been recognized as an issue of emerging concern that might adversely affect wildlife and cause potential risk to the health of marine ecosystems. In addition, preliminary works demonstrated that microplastics are ubiquitously present in many inland waters with concentrations comparable or higher than those observed in marine environments. Asia is the most populous continent in the world, and most Asian countries are under rapid development while facing serious environmental problems. In this chapter, we review the available literature reporting on the occurrence of microplastics in inland waters in Asia. Limited works have provided basic information on the occurrence, distribution, and properties of microplastics in lakes, reservoirs, and estuaries in Asia. Comparison with data from other regions worldwide suggests that microplastic pollution in inland waters in Asia can be more serious. These preliminary results call for more research efforts to better characterize the sources, fate, effects, and risks of microplastics in inland waters. Extensive and in-depth studies are urgently needed to bridge the knowledge gaps to enable a more comprehensive risk assessment of microplastics in inland waters and to support the development of policy addressing this issue.
\end{abstract}

Keywords Asia, Lakes, Microplastics, Occurrence, Rivers, Source

C. Wu (两), K. Zhang, and X. Xiong

Institute of Hydrobiology, Chinese Academy of Sciences, Wuhan 430072, China

e-mail: chenxi.wu@ihb.ac.cn 


\section{Introduction}

Plastics are the most versatile materials invented by man. The use of plastic materials has brought great convenience to our daily lives but not without downsides [1]. Inappropriate disposal of wasted plastics has caused serious environmental problems. The presence of plastic debris in the environment not only affects the aesthetical and recreational values of ecosystems but may also present a persistent pollution problem that will continue to accumulate into future generations [2-4]. Once entering the environment, plastics are subject to physical, chemical, and biological weathering processes, which act to slowly break large pieces of plastic into smaller fragments. Plastics less than $5 \mathrm{~mm}$ are considered as "microplastics" [5]. However, no universally accepted definition in terms of the size range for microplastics is currently available [6]. Microplastics can be ingested by aquatic organisms, which might cause potential adverse effects and arouse food safety concerns [7-10]. As a result, microplastic pollution has become an issue of emerging concern and is drawing increasing attention from both the public and scientific community.

Microplastic pollution in the marine environment has received widespread attention. Microplastics are found ubiquitously in benthic and pelagic environments in the oceans $[11,12]$. In oceans, the high abundance of microplastics observed in the large-scale subtropical convergence zones is attributed to the circulation of ocean currents [13-15]. Accumulation of microplastics in shoreline sediments has also been observed worldwide [16-19]. The majority of plastic debris in oceans originates from land, although discharges from ocean vessels, military operations, and general shipping activities cannot be discounted [20]. It was estimated that 275 million metric tons of plastic wastes were generated in 192 coastal countries in 2010, and about 4.8-12.7 million metric tons are estimated to end up in the ocean [20]. Based on this estimation, over $95 \%$ of the plastic wastes will remain on continents to be either recycled, disposed of in landfills, go for incineration (with or without energy recovery), or otherwise be discarded and stay on continents [21].

Only a few studies have addressed the issue of microplastic pollution in terrestrial environments and inland waters in contrast to the vast amount of research in marine environments. These studies suggest inland waters are facing similar microplastic accumulation problems as found in the oceans [22, 23]. Many inland waters are habitats for aquatic species that have important ecological and economic value and provide services for recreation, aquatic products, and water resources. Therefore, it is important to understand the occurrence, fate, and effects of microplastics in inland waters [24-26].

Asia is the largest and the most populous continent in the world. Asia covers about $30 \%$ of Earth's total land area and supports about $60 \%$ of the world's population. There are about a 1,000 ethnic groups with diverse languages and cultures. Nearly all countries in Asia are developing countries, which are under rapid development while facing growing environmental problems at the same time. In this chapter, we reviewed the available literature on microplastic pollution in inland waters with a specific focus on Asia. A considerable lack of data for inland 
waters was found. Extensive and in-depth studies are urgently needed to bridge the knowledge gaps to enable a more comprehensive risk assessment of microplastics in inland waters and to support the development of policy addressing this issue.

\section{Production and Use of Plastics in Asia}

According to the data from Plastics Europe [27], world production of plastics reached 311 million metric tons in 2014, an increase of 38\% from 2004. China and Japan are the two leading countries with the highest plastic production in Asia accounting for $26 \%$ and $4 \%$ of the world's total production in 2014 , respectively. Plastic production in the rest of Asia accounted for $16 \%$ of the world production. All together Asia produced nearly a half of the world's plastic materials in 2014. These plastic materials are used in a wide variety of markets, including packaging, building and construction, automotive, electrical and electronic, agriculture, consumer and household appliance, etc. Polypropylene (PP), polyethylene (PE), and polyvinyl chloride (PVC) are the most-used polymer types and account for $19.2 \%$, $29.3 \%$, and $10.3 \%$ of the plastics demand in Europe, respectively [27]. Although the production of plastics is the highest in Asia, the per capita consumption is low compared to developed regions. For example, the per capita plastic consumption is 9.7 and $45 \mathrm{~kg}$ per person in India and China, comparing to 65 and $109 \mathrm{~kg}$ per person in Europe and the USA [28].

Plastic wastes are recycled at a much lower ratio in developing countries than in developed countries. In China, less than $10 \%$ of the plastic wastes are recycled, while about $30 \%$ of the plastic wastes are recycled in Europe [27, 29]. What's more, developing countries usually have a high percentage of mismanaged plastic waste. Among the top 20 countries ranked by the mass of mismanaged plastic waste, all of them are developing countries except the USA which has the highest waste generation rate but the lowest percentage of mismanaged plastic waste [20]. Twelve Asian countries were on the list with China, Indonesia, and the Philippines ranked top three. The percentage of mismanaged plastic waste among these Asian countries varied from 1.0 to $27.7 \%$. As a result the environmental release of plastic wastes is more likely in these Asian countries.

\section{Microplastics in Inland Waters in Asia}

\subsection{Occurrence of Microplastics}

Although inland waters in Asia have a high potential to be polluted by microplastics, relevant studies are scarce among the literature. Only seven studies were found from the databases accessible to us and are summarized in Table 1. Among these studies, one was carried out in Mongolia, while all others were performed in 


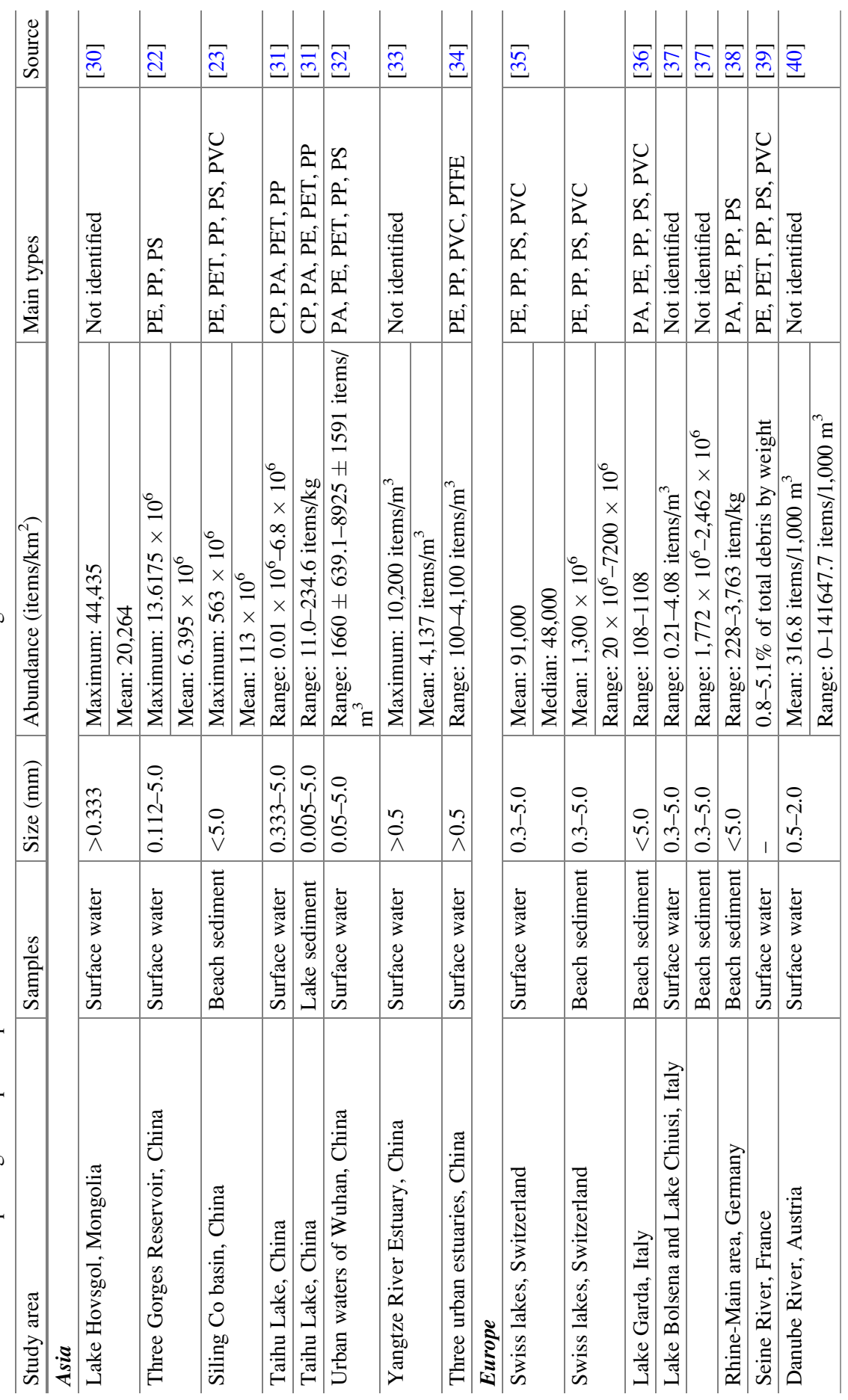




\begin{tabular}{|c|c|c|c|c|c|c|c|c|c|c|c|}
\hline & $\bar{\Xi}$ & & & $\vec{I}$ & 胥 & $\overline{\mathcal{I}}$ & 导害 & 勇 & 焉 & 亦 & 㐫 \\
\hline$\underset{\mathbb{E}}{\mathbb{E}}$ & 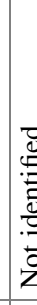 & & 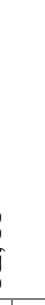 & 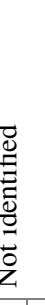 & 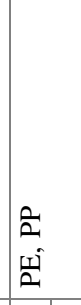 & 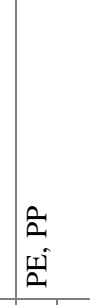 & 띨 떰 & 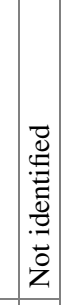 & 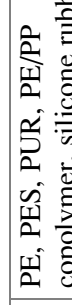 & & $\approx$ \\
\hline స్ & & & & & 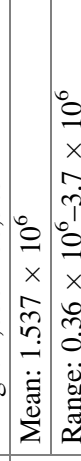 & 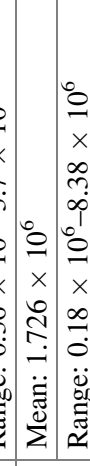 & 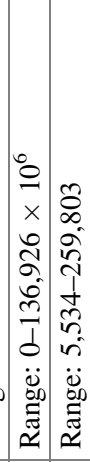 & 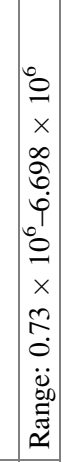 & 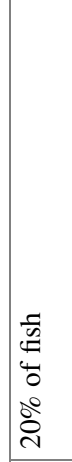 & 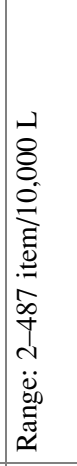 & 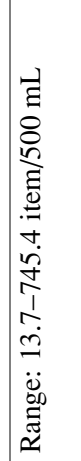 \\
\hline $\begin{array}{l}n \\
\tilde{n} \\
\hat{i} \\
i\end{array}$ & & & 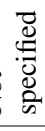 & $\hat{\delta}$ & 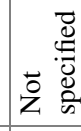 & 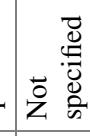 & 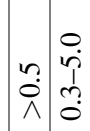 & $\begin{array}{l}m \\
\stackrel{2}{2} \\
\grave{\lambda}\end{array}$ & $\begin{array}{l}\text { rn } \\
\stackrel{\lambda}{\wedge}\end{array}$ & 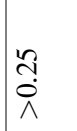 & $\begin{array}{l}\tilde{O} \\
\dot{\lambda} \\
\end{array}$ \\
\hline 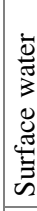 & & & & 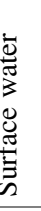 & 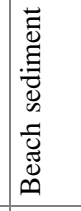 & 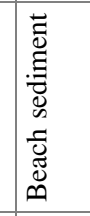 & 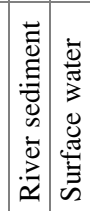 & 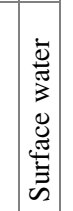 & $\frac{\bar{v}}{\frac{5}{10}}$ & 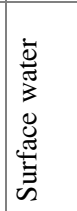 & 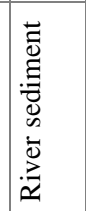 \\
\hline & & & & 语 & 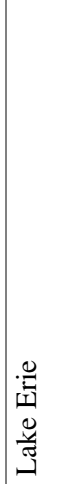 & 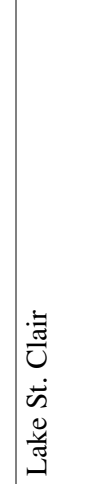 & 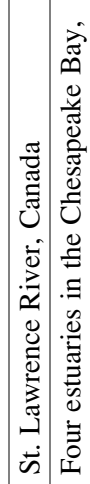 & 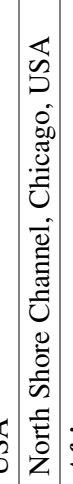 & 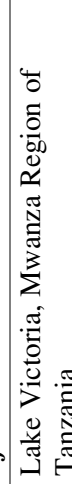 & 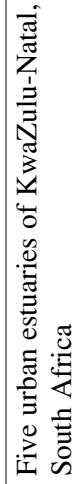 & 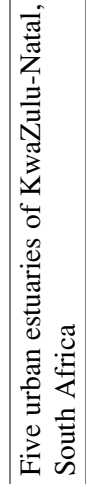 \\
\hline
\end{tabular}


China. Lake Hovsgol, a remote mountain lake in Mongolia, was surveyed for pelagic microplastics [30]. Results showed that microplastic abundance ranged from 997 to 44,435 items $/ \mathrm{km}^{2}$. Microplastic abundance decreased with distance from the southwestern shore which had the highest human impact and was distributed by the prevailing winds. Zhang et al. [22] investigated microplastic occurrence in the surface waters of the Three Gorges Reservoir in China and found microplastic abundance up to $136,175 \times 10^{6}$ items $/ \mathrm{km}^{2}$, which is the highest microplastic abundance ever reported in the literature. The authors suggested that the high accumulation of microplastics is related to the damming, and reservoirs can act as potential hot spots for microplastics. In another study by Zhang et al. [23], microplastics were sampled from the shorelines of four lakes within the Siling Co basin in northern Tibet. Microplastics were detected in six out of seven sampling sites, and the site with the highest microplastic abundance was related to the riverine input. Su et al. [31] reported microplastic pollution in Taihu Lake, which is the third largest freshwater lake in China located in a well-developed area under extensive human influence. Microplastics were detected in plankton net, surface water, sediment, and Asian clams samples. More recently, microplastic pollution was studied in inland freshwaters in Wuhan, the largest city in Central China [32]. Microplastics were detected with concentrations ranged from 1,660 \pm 639.1 to $8,925 \pm 1,591$ items $/ \mathrm{m}^{3}$ in surface water, and microplastic abundance was negatively correlated with the distance from the city center. Another two studies have also investigated the occurrence of microplastics in surface water from the estuaries of Yangtze, Jiaojiang, Oujiang, and Minjiang in China [33, 34]. Results demonstrated that microplastics were present in high abundance in these transitional zones between rivers and the sea and suggested that rivers are important sources of microplastics to marine environment.

The literature reporting the occurrence of microplastics in inland waters from other geographical regions is also summarized in Table 1. A comparison of data from different regions can be challenging due to the difference in sampling methods used, size ranges investigated, and the reporting units that are employed. Therefore, it is urgently needed to adopt universal criteria for sampling and reporting microplastics occurrence data to facilitate a comparison [49]. Additionally, the abundance of microplastics from different regions differs by several orders of magnitude. Even within the same region, the abundance of microplastics varies considerably. This uneven distribution pattern can be related to their relatively low density, which means that they can be transported easily with the current and accumulation in areas with weaker hydrodynamic conditions. In addition, the loading rate of plastic waste can differ significantly in different regions. Previously, Yonkos et al. [45] demonstrated that the abundance of microplastics was positively correlated with population density and proportion of urban/suburban development within the watersheds. However, researches also demonstrated that microplastics were also found at relatively high concentrations in inland waters from remote areas with limited human activities [23,30]. This is likely due to a lack of proper waste management measures in those areas. In many Asian countries, high population density and unsound waste management systems lead to a high risk of inland water 
pollution by microplastics as well as many other pollutants. This might explain the very high abundance of microplastics observed in Taihu Lake and Three Gorges Reservoirs in China. Therefore, inland waters in Asia deserve more attention in the future.

\subsection{Characteristics of the Microplastics}

\subsubsection{Particle Shape}

After sample collection, potential microplastics are usually examined using stereo microscopes. According to their shapes, microplastics are typically categorized as follows: sheet, film, line/fiber, fragment, pellet/granule, and foam (Fig. 1). However, there is no set protocol, and different classifications might be used by different researchers. This morphological information from the microplastic samples can be used to indicate their potential origins. For example, line/fiber usually originates from fishing lines, clothing, or other textiles, while film mainly originates from bags or wrapping materials. In Lake Hovsgol, fragments and films were found to be the most abundant, together accounting for $78 \%$ of the total microplastics [31]. In the Three Gorges Reservoir, sheet particles and miscellaneous fragments were dominant in most sites [22], whereas fibers and fragments were predominant in samples from Taihu Lake [31]. In inland freshwaters of Wuhan, fiber, granule, film, and pellet were commonly detected, and fibers were most frequently detected accounting for 52.9-95.6\% of the total plastics [32]. For microplastic samples from the four estuaries in China, fibers and granules were the more abundant [33, 34]. Different patterns observed in these study areas suggest that the sources of the microplastics

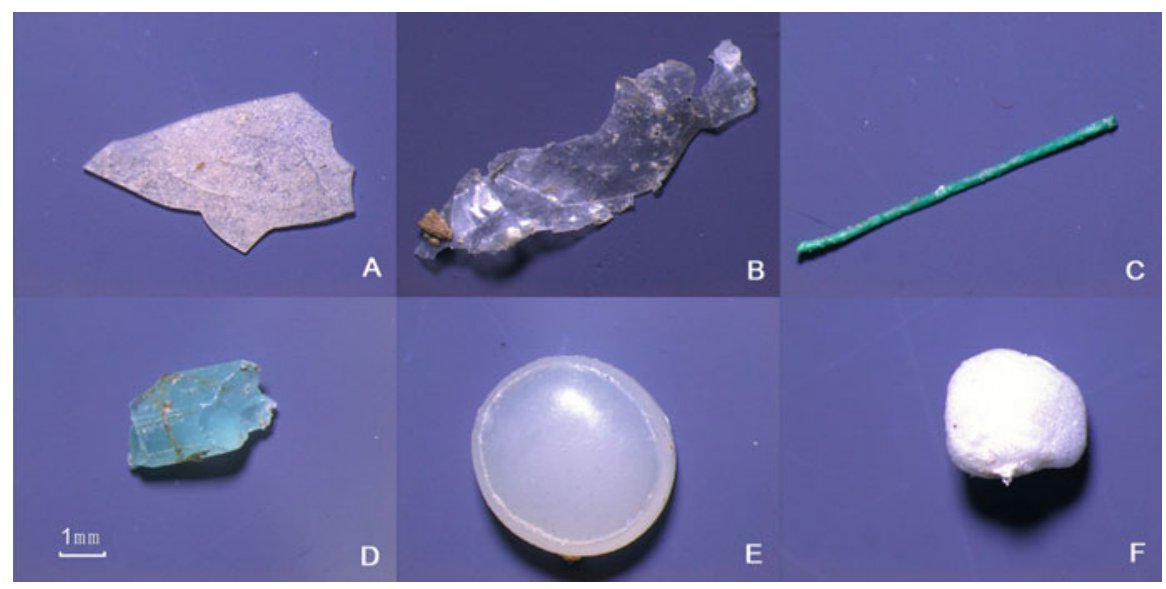

Fig. 1 Shapes of typical microplastics collected from inland waters (Qinghai Lake and Three Gorges Reservoir) in China (a, sheet; b, film; c, line/fiber; $\mathbf{d}$, fragment; e, pellet/granule; f, foam) 
might differ considerably in different regions. Fibers appeared to be more abundant in more populated areas.

\subsubsection{Particle Size}

Size is another parameter usually measured for microplastics, but no unified criteria are currently available. Different size classes were reported by different authors, which make it difficult to compare the data from different works [50]. Due to the restriction of the sampling methods used, usually only microplastics $>0.333 \mathrm{~mm}$ (mesh size of the manta trawl net) are assessed in neustonic samples collected by trawling. Smaller microplastics can be examined for sediment and biota samples as density separation combined with filtration is used. Whereas the examination of microplastics $<0.05 \mathrm{~mm}$ will get increasingly difficult, advanced instruments such as Raman microscopy, micro-Fourier transform infrared spectroscopy ( $\mu$-FTIR), or scanning electron microscope (SEM) with energy dispersive spectroscopy (EDS) should be used [36]. Generally, microplastic abundance increases with decreasing size [51-53]. In lake Hovsgol, 0.355-0.999, 1.00-4.749, and $>4.75 \mathrm{~mm}$ size classes accounted for 41,40 , and $19 \%$ of the total plastics, respectively [30]. In the freshwaters of Wuhan, $0.05-0.5,0.5-1$, and $1-2 \mathrm{~mm}$ size classes together accounted for over $80 \%$ of the total microplastics, and $0.05-0.5 \mathrm{~mm}$ microplastics were the most abundant in most of the studied waters [32]. In Yangtze Estuary, $0.5-1,1-2.5,2.5-5$, and $>5 \mathrm{~mm}$ size classes made up $67,28.4,4.4$, and $0.2 \%$ of the total plastics, respectively [33]. In the estuary of Minjiang, Oujiang, and Jiaojiang, the smallest size class $(0.5-1.0 \mathrm{~mm})$ was also found the most abundant followed by the 1.0-2.0 mm size class, and these two size classes together accounted for over $70 \%$ of the total plastics [34]. However, among the four size classes $(0.112-0.3$, $0.3-0.5,0.5-1.6,1.6-5 \mathrm{~mm}), 0.5-1.6 \mathrm{~mm}$ microplastics were the most abundant from the majority of site in the Three Gorges Reservoir, which made up 30-57\% of the total microplastics [22]. While for microplastic samples from the lakeshore sediment of the Siling Co basin, different size distribution patterns were observed from different sampling sites [23]. The patterns of microplastic size distribution can be related to the sources of microplastics and might also reflect the degree of weathering. A higher degree of weathering might result in a higher abundance of smaller particles. Biofouling and hydrodynamic conditions were also believed to affect the size distribution of microplastics [54-56].

\subsubsection{Color}

In some studies, colors of the microplastics were described. Microplastics can inherit their colors from their parent plastic products, but their colors can change due to weathering. Previous research infers that predators may preferably ingest microplastics with colors resembling their prey [57-59]. Therefore, color information of microplastics may be used to indicate their potential to be ingested by 
aquatic animals. In Taihu Lake, recovered microplastics were found in a variety of colors including transparent, black, white, red, yellow, green, and blue [31]. In addition, blue was the most dominant color in plankton net and surface water samples, while white microplastics were the most abundant in sediments [31]. In the freshwaters of Wuhan, microplastics were found to be transparent or in blue, purple, red, or other colors, and colored microplastics, accounting for 50.4-86.9\% of the total microplastics, were more abundant than transparent ones [32]. From the estuaries of Jiaojiang, Oujiang, and Minjiang, microplastics were divided into transparent, white, black, and colored groups, and colored microplastics were identified as the most dominant [34]. It may be interesting to investigate further how color affects the environmental fate and ecological effects of microplastics. As an example, colorants can often influence the final thermal and UV stability of a plastic material $[60,61]$.

\subsubsection{Surface Texture}

Once entering the environment, plastics are subject to weathering processes, and these processes will influence the surface of the microplastics (Fig. 2). Featured surface textures on microplastics can be used to indicate the processes of mechanical and oxidative weathering $[62,63]$. Surface textures are usually examined using SEM. Features such as grooves, fractures, and mechanical pits are believed to result from mechanical weathering, while flakes, granules, and solution pits are considered as oxidative weathering features [43]. The surface oxidation of plastics can be confirmed using FTIR as indicated by the appearance of peaks for carbonyl groups [31, 43]. Zhang et al. [23] examined the surface textures of microplastics from the lakeshore sediments of the Siling Co basin, and mechanical weathering features were more often observed, which were attributed to the windy weather condition in the study area. This result agrees with the overall trend of microplastics recovered from the Great Lakes, but differs from those recovered from beach sands in Hawaii $[43,63]$. Hawaii has a warmer and more humid climate than northern Tibet and the Great Lakes region and might therefore favor the oxidative weathering of the plastics.

\subsection{Polymer Types Found}

A variety of polymers were used in the production of plastics. Properties and performances of the plastic materials are largely determined by the polymer types they are made of. Thus, polymer types can have a great impact on the longevity and buoyancy of microplastics, thus affecting their fate in the environment. Polymer types are typically identified using FTIR and Raman spectrometry, and less often pyrolysis-gas chromatography/mass spectrometry (Pyr-GC/MS) is used $[64,65]$. Detailed reviews of the typically used techniques for the 


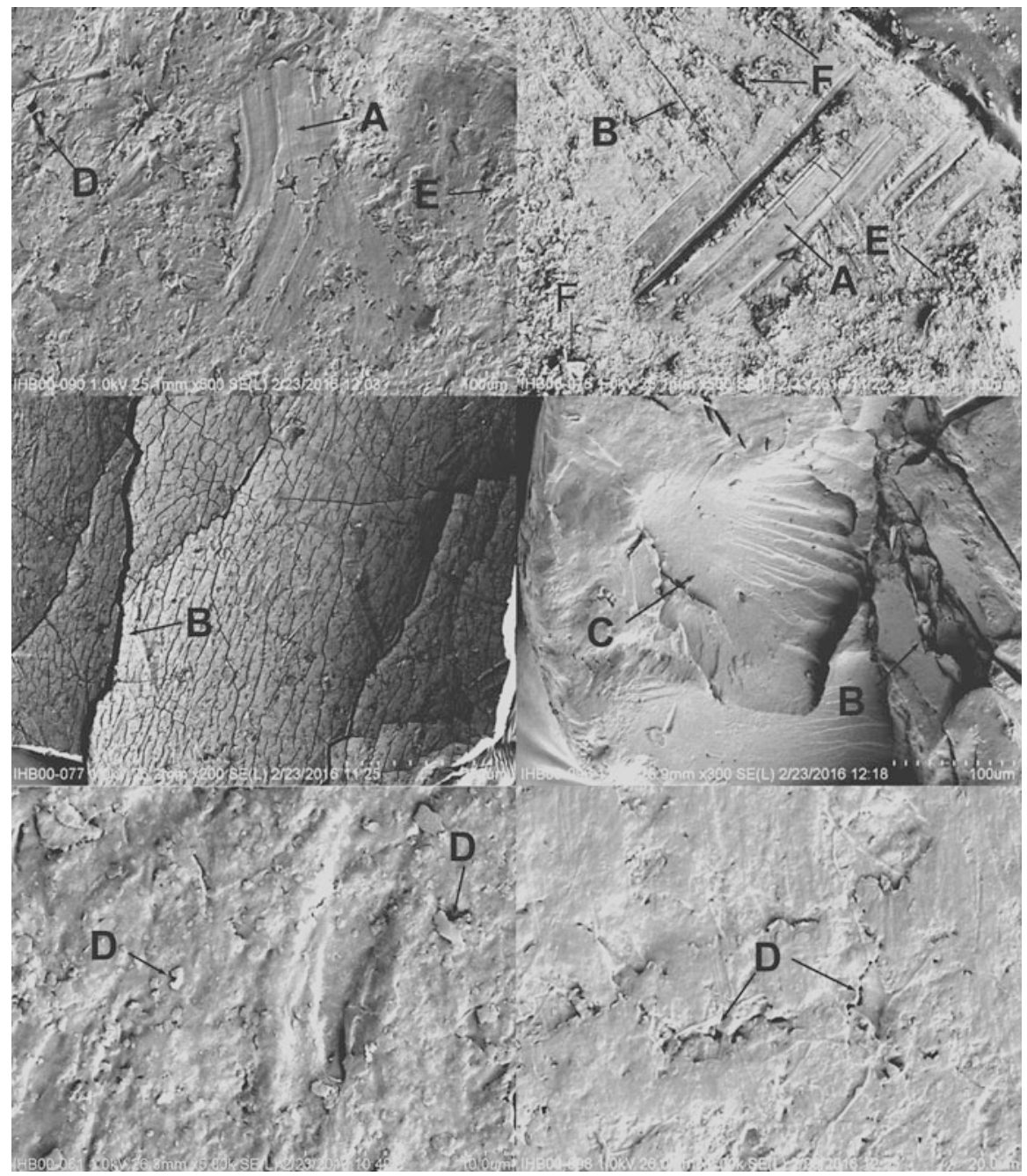

Fig. 2 Surface texture of typical microplastics collected from inland waters (Siling Co Basin) in China (a, grooves; b, fractures; c, mechanical pits; d, flakes; e, granular; f, solution pits)

identification of microplastics were published recently [66-68]. An overview of the advantages and limitations of these techniques is summarized in Table 2.

In the Three Gorges Reservoir, only PE, PP, and PS were identified from the recovered microplastics, which may be related to their lower density. The weak hydraulic conditions of the Three Gorges Reservoir will generally favor the sedimentation of microplastics originating from denser polymer types [22]. In lakeshore sediments from Siling Co basin, PE and PP were predominant, while PVC, PET, and PS were only identified from one sampling site [23]. Whereas cellophane (CP) which is a transparent material made of regenerated cellulose was found to 
Table 2 Advantages and limitations of commonly used techniques for the identification of microplastics from environmental samples

\begin{tabular}{l|l|l|l}
\hline Technique & Size & Advantages & Limitations \\
\hline ATR-FTIR & $>1 \mathrm{~mm}$ & Easy simple preparation; low cost & $\begin{array}{l}\text { Unable to identify small sam- } \\
\text { ples; unsuitable for convex par- } \\
\text { ticles or severely aged or } \\
\text { contaminated samples }\end{array}$ \\
\hline$\mu$-FTIR & $>10 \mu \mathrm{m}$ & Suitable for small samples & $\begin{array}{l}\text { Sample preparation is complex; } \\
\text { unable to analyze polyamides; } \\
\text { high cost }\end{array}$ \\
\hline $\begin{array}{l}\text { FPA-based } \\
\mu \text {-FTIR } \\
\text { Raman } \\
\text { spectroscopy }\end{array}$ & $>20 \mu \mathrm{m}$ & $\begin{array}{l}\text { Suitable for small samples; no } \\
\text { need for visual sorting }\end{array}$ & Time consuming; high cost \\
\hline CARS & $>1 \mu \mathrm{m}$ & $\begin{array}{l}\text { Suitable for very small samples; } \\
\text { lower water interference }\end{array}$ & $\begin{array}{l}\text { Sensitive to fluorescence inter- } \\
\text { ference; laser-induced degrada- } \\
\text { tion; high cost }\end{array}$ \\
\hline $\begin{array}{l}\text { Applicable to living organisms; } \\
\text { minimal or no sample prepara- } \\
\text { tion; strong signal; less } \\
\text { interference }\end{array}$ & Very high cost \\
\hline Pyr-GC/MS & $>0.1 \mathrm{mg}$ & $\begin{array}{l}\text { Organic plastic additive can be } \\
\text { analyzed }\end{array}$ & Destructive; time consuming \\
\hline
\end{tabular}

ATR attenuated total reflectance, FPA focal plane array, CARS coherent anti-Stokes Raman scattering

be the most abundant in Taihu Lake likely due to a low biodegradability of the material [31]. In the freshwaters of Wuhan, PET, PP, PE, PA, and PS were identified, and PET and PP were more abundant [32]. From the estuaries of Jiaojiang, Oujiang, and Minjiang, selected microplastics were found mostly PP and PE [33], which agrees with the result from the Three Gorges Reservoir. Frequent detection of PP and PE was also reported in many other works [36, 45, $69,70]$. This can be related to their low density, meaning these polymer types are buoyant and readily transported with water. In addition, a larger global demand for $\mathrm{PE}$ and PP makes them more prevalent in the environment.

\section{Conclusions}

Inland waters are facing similar issues as marine environments with regard to microplastics. Analysis suggests that inland waters in many Asian countries have a high risk to be polluted by microplastics. However, only limited works have been performed in investigating microplastic occurrence in inland waters in Asia currently. Available researches have demonstrated the presence of microplastics in lakes, reservoirs, and river estuaries. The abundances of microplastics in the Three Gorges Reservoir and Taihu Lake in China are among the highest reported data in inland waters worldwide. Relatively high abundance of microplastic was also 
observed in lakes from remote areas in Mongolia and in central Tibet. Waste management systems need to be improved in these developing Asian countries to mitigate the microplastic pollution problems. Along with abundance, features of microplastic samples such as shapes, sizes, colors, surface textures, and polymer types were measured in these studies, which can be used to interpret the origins and experiences of the microplastics. These preliminary results call for further research efforts to better understand the sources and fate of microplastics in inland waters. The biological and ecological risk of microplastic exposure should be assessed especially at environmentally relevant circumstances. Sampling, pretreatment, and reporting of microplastics should be standardized for the future monitoring programs.

\section{References}

1. Andrady AL, Neal MA (2009) Applications and societal benefits of plastics. Philos Trans R Soc B Biol Sci 364(1526):1977-1984

2. Wright SL, Thompson RC, Galloway TS (2013) The physical impacts of microplastics on marine organisms: a review. Environ Pollut 178:483-492

3. Bakir A, Rowland SJ, Thompson RC (2014) Enhanced desorption of persistent organic pollutants from microplastics under simulated physiological conditions. Environ Pollut 185: $16-23$

4. Yang CZ, Yaniger SI, Jordan VC, Klein DJ, Bittner GD (2011) Most plastic products release estrogenic chemicals: A potential health problem that can be solved. Environ Health Perspect 119(7):989-996

5. Arthur C, Baker J, Bamford H (eds) (2008) Proceedings of the international research workshop on the occurrence, effects and fate of microplastic marine debris. NOAA technical memorandum NOS-OR\&R-30, 9-11 Sept 2008

6. Hidalgo-Ruz V, Gutow L, Thompson RC, Thiel M (2012) Microplastics in the marine environment: a review of the methods used for identification and quantification. Environ Sci Technol 46(6):3060-3075

7. Rochman CM, Hoh E, Kurobe T, Teh SJ (2013) Ingested plastic transfers hazardous chemicals to fish and induces hepatic stress. Sci Rep 3:3263

8. Browne MA, Dissanayake A, Galloway TS, Lowe DM, Thompson RC (2008) Ingested microscopic plastic translocates to the circulatory system of the mussel, Mytilus edulis (L.) Environ Sci Technol 42(13):5026-5031

9. Seltenrich N (2015) New link in the food chain? Marine plastic pollution and seafood safety. Environ Health Perspect 123(2):A34-A41

10. da Costa JP, Santos PSM, Duarte AC, Rocha-Santos T (2016) (Nano)plastics in the environment - sources, fates and effects. Sci Total Environ 566-567:15-26

11. Ivar do Sul JA, Costa MF (2014) The present and future of microplastic pollution in the marine environment. Environ Pollut 185:352-364

12. Van Cauwenberghe L, Devriese L, Galgani F, Robbens J, Janssen CR (2015) Microplastics in sediments: a review of techniques, occurrence and effects. Mar Environ Res 111:5-17

13. Law KL, Morét-Ferguson S, Maximenko NA, Proskurowski G, Peacock EE, Hafner J, Reddy CM (2010) Plastic accumulation in the North Atlantic subtropical gyre. Science 329(5996): $1185-1188$ 
14. Eriksen M, Maximenko N, Thiel M, Cummins A, Lattin G, Wilson S, Hafner J, Zellers A, Rifman S (2013) Plastic pollution in the South Pacific subtropical gyre. Mar Pollut Bull 68(1-2):71-76

15. Cózar A, Echevarría F, González-Gordillo JI, Irigoien X, Úbeda B, Hernández-León S, Palma AT, Navarro S, García-de-Lomas J, Ruiz A, Fernández-de-Puelles ML, Duarte CM (2014) Plastic debris in the open ocean. Proc Natl Acad Sci 111(28):10239-10244

16. Browne MA, Crump P, Niven SJ, Teuten E, Tonkin A, Galloway T, Thompson R (2011) Accumulation of microplastic on shorelines worldwide: sources and sinks. Environ Sci Technol 45(21):9175-9179

17. Jayasiri HB, Purushothaman CS, Vennila A (2013) Quantitative analysis of plastic debris on recreational beaches in Mumbai, India. Mar Pollut Bull 77(1-2):107-112

18. Smith SDA, Gillies CL, Shortland-Jones H (2014) Patterns of marine debris distribution on the beaches of Rottnest Island, Western Australia. Mar Pollut Bull 88(1-2):188-193

19. Lee J, Hong S, Song YK, Hong SH, Jang YC, Jang M, Heo NW, Han GM, Lee MJ, Kang D, Shim WJ (2013) Relationships among the abundances of plastic debris in different size classes on beaches in South Korea. Mar Pollut Bull 77(1-2):349-354

20. Jambeck JR, Geyer R, Wilcox C, Siegler TR, Perryman M, Andrady A, Narayan R, Law KL (2015) Plastic waste inputs from land into the ocean. Science 347(6223):768-771

21. Rochman CM, Browne MA, Halpern BS, Hentschel BT, Hoh E, Karapanagioti HK, RiosMendoza LM, Takada H, Teh S, Thompson RC (2013) Policy: classify plastic waste as hazardous. Nature 494(7436):169-171

22. Zhang K, Gong W, Lv J, Xiong X, Wu C (2015) Accumulation of floating microplastics behind the three Gorges dam. Environ Pollut 204:117-123

23. Zhang K, Su J, Xiong X, Wu X, Wu C, Liu J (2016) Microplastic pollution of lakeshore sediments from remote lakes in Tibet plateau, China. Environ Pollut 219:450-455

24. Wagner M, Scherer C, Alvarez-Muñoz D, Brennholt N, Bourrain X, Buchinger S, Elke F, Grosbois C, Klasmeier J, Marti T, Rodriguez-Mozaz S, Urbatzka R, Vethaak AD, WintherNielsen M, Reifferscheid G (2014) Microplastics in freshwater ecosystems: what we know and what we need to know. Environ Sci Eur 26(1):1-9

25. Eerkes-Medrano D, Thompson RC, Aldridge DC (2015) Microplastics in freshwater systems: a review of the emerging threats, identification of knowledge gaps and prioritisation of research needs. Water Res 75:63-82

26. Lambert S, Sinclair C, Boxall A (2014) Occurrence, degradation, and effect of polymer-based materials in the environment. In: Whitacre DM Reviews of environmental contamination and toxicology, vol 227. Springer, Cham, pp 1-53

27. PlasticsEurope (2015) Plastics-the facts 2015: an analysis of European plastics production, demand and waste data. http://www.plasticseurope.org

28. TataStrategic (2014) Potential of plastics industry in Northern India with special focus on plasticulture and food processing-2014. A report on plastics industry. Federation of Indian Chambers of Commerce and Industry. New Delhi

29. Tang G, Hu B, Kang Z, Meng C, Zhang X, Zhang L, Feng HY, Sun WP (2013) Current status and problems on waste plastic recycling. Recy Resour Circ Econ 6(1):31-35. (In Chinese with English Abstract)

30. Free CM, Jensen OP, Mason SA, Eriksen M, Williamson NJ, Boldgiv B (2014) High-levels of microplastic pollution in a large, remote, mountain lake. Mar Pollut Bull 85(1):156-163

31. Su L, Xue Y, Li L, Yang D, Kolandhasamy P, Li D, Shi H (2016) Microplastics in Taihu Lake, China. Environ Pollut. doi:10.1016/j.envpol.2016.06.036

32. Wang W, Ndungu AW, Li Z, Wang J (2016) Microplastics pollution in inland freshwaters of China: a case study in urban surface waters of Wuhan, China. Sci Total Environ. doi:10.1016/j. scitotenv.2016.09.213

33. Zhao S, Zhu L, Wang T, Li D (2014) Suspended microplastics in the surface water of the Yangtze estuary system, China: first observations on occurrence, distribution. Mar Pollut Bull 86(1-2):562-568 
34. Zhao S, Zhu L, Li D (2015) Microplastic in three urban estuaries, China. Environ Pollut 206:597-604

35. Faure F, Corbaz M, Baecher H, de Alencastro L (2012) Pollution due to plastics and microplastics in Lake Geneva and in the Mediterranean Sea. Arch Sci 65:157-164

36. Imhof HK, Ivleva NP, Schmid J, Niessner R, Laforsch C (2013) Contamination of beach sediments of a subalpine lake with microplastic particles. Curr Biol 23(19):R867-R868

37. Fischer EK, Paglialonga L, Czech E, Tamminga M (2016) Microplastic pollution in lakes and lake shoreline sediments - a case study on Lake Bolsena and lake Chiusi (central Italy). Environ Pollut 213:648-657

38. Klein S, Worch E, Knepper TP (2015) Occurrence and spatial distribution of microplastics in river shore sediments of the Rhine-Main area in Germany. Environ Sci Technol 49(10): 6070-6076

39. Gasperi J, Dris R, Bonin T, Rocher V, Tassin B (2014) Assessment of floating plastic debris in surface water along the Seine River. Environ Pollut 195:163-166

40. Lechner A, Keckeis H, Lumesberger-Loisl F, Zens B, Krusch R, Tritthart M, Glas M, Schludemann E (2014) The Danube so colourful: a potpourri of plastic litter outnumbers fish larvae in Europe's second largest river. Environ Pollut 188:177-181

41. Sadri SS, Thompson RC (2014) On the quantity and composition of floating plastic debris entering and leaving the Tamar estuary, Southwest England. Mar Pollut Bull 81(1):55-60

42. Eriksen M, Mason S, Wilson S, Box C, Zellers A, Edwards W, Farley H, Amato S (2013) Microplastic pollution in the surface waters of the Laurentian Great Lakes. Mar Pollut Bull 77(1-2):177-182

43. Zbyszewski M, Corcoran PL, Hockin A (2014) Comparison of the distribution and degradation of plastic debris along shorelines of the Great Lakes, North America. J Great Lakes Res 40(2): 288-299

44. Castañeda RA, Avlijas S, Simard MA, Ricciardi A (2014) Microplastic pollution in St. Lawrence River sediments. Can J Fish Aquat Sci 71(12):1767-1771

45. Yonkos LT, Friedel EA, Perez-Reyes AC, Ghosal S, Arthur CD (2014) Microplastics in four estuarine rivers in the Chesapeake bay, USA. Environ Sci Technol 48(24):14195-14202

46. McCormick A, Hoellein TJ, Mason SA, Schluep J, Kelly JJ (2014) Microplastic is an abundant and distinct microbial habitat in an urban river. Environ Sci Technol 48(20):11863-11871

47. Biginagwa FJ, Mayoma BS, Shashoua Y, Syberg K, Khan FR (2016) First evidence of microplastics in the African Great Lakes: recovery from Lake Victoria Nile perch and Nile tilapia. J Great Lakes Res 42(1):146-149

48. Naidoo T, Glassom D, Smit AJ (2015) Plastic pollution in five urban estuaries of KwaZuluNatal, South Africa. Mar Pollut Bull 101(1):473-480

49. Phuong NN, Zalouk-Vergnoux A, Poirier L, Kamari A, Châtel A, Mouneyrac C, Lagarde F (2016) Is there any consistency between the microplastics found in the field and those used in laboratory experiments? Environ Pollut 211:111-123

50. Filella M (2015) Questions of size and numbers in environmental research on microplastics: methodological and conceptual aspects. Environ Chem 12(5):527-538

51. Collignon A, Hecq JH, Galgani F, Voisin P, Collard F, Goffart A (2012) Neustonic microplastic and zooplankton in the North Western Mediterranean Sea. Mar Pollut Bull 64(4): 861-864

52. Isobe A, Uchida K, Tokai T, Iwasaki S (2015) East Asian seas: a hot spot of pelagic microplastics. Mar Pollut Bull 101(2):618-623

53. Imhof HK, Laforsch C, Wiesheu AC, Schmid J, Anger PM, Niessner R, Ivleva NP (2016) Pigments and plastic in limnetic ecosystems: a qualitative and quantitative study on microparticles of different size classes. Water Res 98:64-74

54. Isobe A, Kubo K, Tamura Y, Si K, Nakashima E, Fujii N (2014) Selective transport of microplastics and mesoplastics by drifting in coastal waters. Mar Pollut Bull 89(1-2):324-330

55. Fazey FMC, Ryan PG (2016) Biofouling on buoyant marine plastics: an experimental study into the effect of size on surface longevity. Environ Pollut 210:354-360 
56. Peter GR (2015) Does size and buoyancy affect the long-distance transport of floating debris? Environ Res Lett 10(8):084019

57. Boerger CM, Lattin GL, Moore SL, Moore CJ (2010) Plastic ingestion by planktivorous fishes in the North Pacific central gyre. Mar Pollut Bull 60(12):2275-2278

58. Moser ML, Lee DS (1992) A fourteen-year survey of plastic ingestion by western North Atlantic seabirds. Colon Waterbird 15(1):83-94

59. Moore CJ (2008) Synthetic polymers in the marine environment: a rapidly increasing, longterm threat. Environ Res 108(2):131-139

60. Saron C, Felisberti MI (2006) Influence of colorants on the degradation and stabilization of polymers. Quím Nova 29(1):124-128

61. Russell S (2003) Color compounding. In: Charvat RA (ed) Coloring of plastics: fundamentals. Wiley, Hoboken

62. Zbyszewski M, Corcoran PL (2011) Distribution and degradation of fresh water plastic particles along the beaches of Lake Huron, Canada. Water Air Soil Pollut 220(1):365-372

63. Cooper DA, Corcoran PL (2010) Effects of mechanical and chemical processes on the degradation of plastic beach debris on the island of Kauai, Hawaii. Mar Pollut Bull 60(5):650-654

64. Rocha-Santos T, Duarte AC (2015) A critical overview of the analytical approaches to the occurrence, the fate and the behavior of microplastics in the environment. TrAC Trends Anal Chem 65:47-53

65. Käppler A, Fisher D, Oberbechmann S, Schernewski G, Labrenz M, Eichhorn KJ, Voit B (2016) Analysis of environmental microplastics by vibrational microspectroscopy: FTIR, Raman or both? Anal Bioanal Chem 408:8377-8391

66. Qiu Q, Tan Z, Wang J, Peng J, Li M, Zhan Z (2016) Extraction, enumeration and identification methods for monitoring microplastics in the environment. Estuar Coast Shelf Sci 176:102-109

67. Ribeiro-Claro P, Nolasco MM, Araújo C (2017) Characterization of microplastics by Raman spectroscopy. Compr Anal Chem 75:119-151

68. Renner G, Schmid TC, Schram J (2017) Characterization and quantification of microplastics by infrared spectroscopy. Compr Anal Chem 75:67-118

69. Veerasingam S, Saha M, Suneel V, Vethamony P, Rodrigues AC, Bhattacharyya S, Naik BG (2016) Characteristics, seasonal distribution and surface degradation features of microplastic pellets along the Goa coast, India. Chemosphere 159:496-505

70. Chae DH, Kim IS, Kim SK, Song YK, Shim WJ (2015) Abundance and distribution characteristics of microplastics in surface seawaters of the Incheon/Kyeonggi coastal region. Arch Environ Con Tox 69(3):269-278

Open Access This chapter is licensed under the terms of the Creative Commons Attribution 4.0 International License (http://creativecommons.org/licenses/by/4.0/), which permits use, sharing, adaptation, distribution and reproduction in any medium or format, as long as you give appropriate credit to the original author(s) and the source, provide a link to the Creative Commons license and indicate if changes were made.

The images or other third party material in this chapter are included in the chapter's Creative Commons license, unless indicated otherwise in a credit line to the material. If material is not included in the chapter's Creative Commons license and your intended use is not permitted by statutory regulation or exceeds the permitted use, you will need to obtain permission directly from the copyright holder.

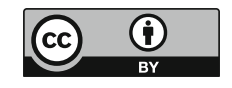

